\title{
Conservation of the black-crested gibbon in China
}

\author{
William Bleisch and Chen Nan
}

The black-crested gibbon is believed to be endangered throughout its range in China and northern Vietnam, where much of the original forest has been destroyed. The only reserves known to have substantial populations are the Ailao Mountain and Wuliang Mountain Natural Protected Areas in Yunnan Province, China, which together may have 1500 of an estimated total of 3500 black-crested gibbons in protected areas in China. Although they are probably the best protected, the gibbon populations of both reserves have been badly depleted by deforestation and hunting. Recent reports that roads will be constructed through the centres of the reserves, and that gold has been discovered in one of them, increase concern. The Ministry of Forestry has started new conservation measures, but further action is required.

The crested gibbons are the least well known of the gibbons. The group includes whitecheeked, red-cheeked and black-crested gibbons, which, until recently, were all considered to be subspecies of Hylobates concolor. However, based on evidence of sympatry and on morphological and behavioural differences, two or more separate species are recognized (Dao, 1983; Ma and Wang, 1986; Groves and Wang, 1988; Ma et al., 1988). Two of these, the white-cheeked gibbon $H$. leucogenys and blackcrested gibbon $H$. concolor, have partially overlapping ranges in China, Laos and Vietnam (Figure 1) (Dao, 1983; Ma and Wang, 1986; Fooden et al., 1987). Black-crested gibbons were once widespread, inhabiting subtropical and montane evergreen forests throughout southern China, in Vietnam north of $20^{\circ}$ latitude and into Laos. White-cheeked gibbons also occur in some of these areas and to the south, but may be restricted to lowland evergreen forests. They can still be found in the Mengla and Shangyong Reserves in China, in Laos, where they may still be relatively abundant, and in Vietnam (MacKinnon and MacKinnon, 1987). However, the subspecies H. l. siki, which has a small range in central Vietnam and adjacent Laos, may be near extinction. The red-cheeked gibbon, H. $l$.

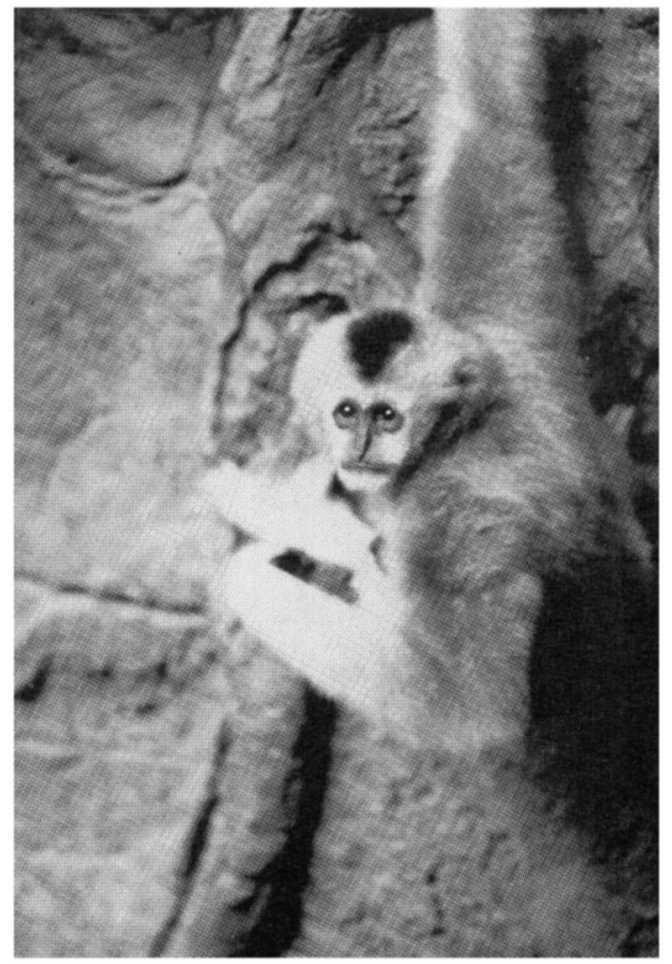

Captive female white-crested gibbon; this species is the closest relative of the black-crested gibbon (W. Bleisch). 
gabrielli occurs in southern Vietnam and Cambodia, where it may still be relatively abundant, although widespread deforestation during the Vietnam conflict and intensive hunting make it important that surveys be performed to determine its status.

All these gibbons are in danger of extinction, primarily because they are found only in undisturbed forests, which are being rapidly depleted. In addition, because of their low reproductive rate, gibbons in isolated forest patches are especially susceptible to overhunting. In China and adjacent countries, gibbons are still hunted for food and for medicinal use. Chinese hunters describe gibbon meat as delicious and rural Chinese consider gibbon bones to be a potent treatment for rheumatism.

\section{Conservation status of black-crested gibbons}

\section{Vietnam}

The currerit status of the black-crested gibbon in Vietnam is unknown, but may be precarious. Forest cover has been greatly reduced in northern Vietnam in recent years and gibbon populations may be quite depleted considering the recent history of this region, including the dissemination of modern weapons. Gibbons have been reported from at least two protected areas, one of which (Nam Cat Tien National Park) is outside the species's range (Dao, 1983). In Cuc Phuong National Park (Constable, 1982; Pfeiffer, 1984) recent surveys

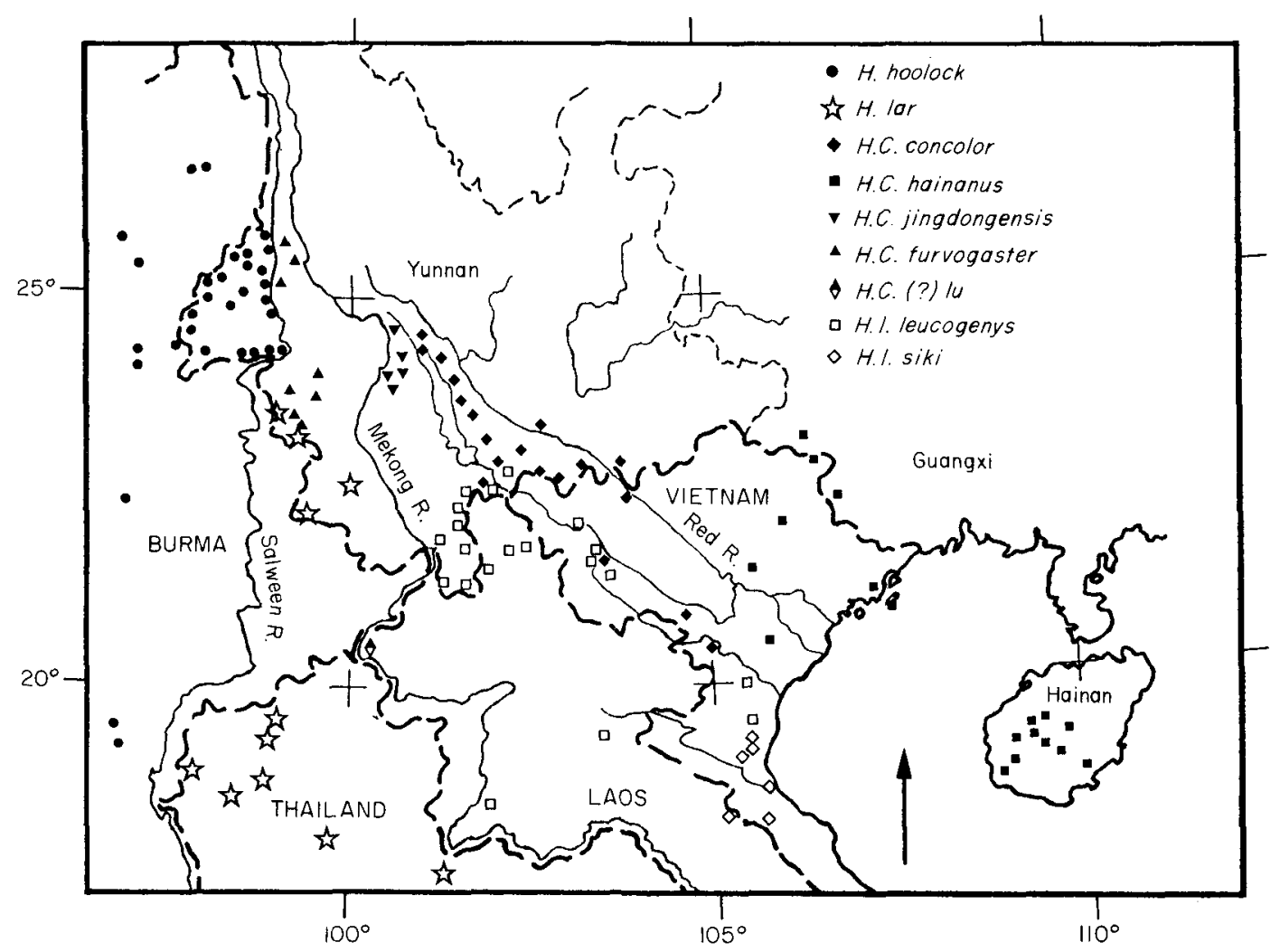

Figure 1. Recent historic distribution of gibbons of various subspecies in China and surrounding regions as determined from museum specimens. Nomenclature follows Ma and Wang (1986); see also Groves and Wang (1988) Ma et al. (1988). Map adapted from Fooden et al. (1987) and Ma and Wang (1986) with additional data from Dao (1983) and Marshall and Sugardjito (1986). 
failed to reveal any evidence of gibbons (MacKinnon and MacKinnon, 1987). Other large recently approved reserves are within the species's range (MacKinnon and MacKinnon, 1986; IUCN, pers. comm.) and it is possible that there may be several hundred black-crested gibbons in the country.

\section{Laos}

The only population of black-crested gibbons in Laos known to us is a small population of the subspecies H. c. $l u$, at a site on the east bank of the Mekong (Figure 1). This population is completely surrounded by H. leucogenys to the east (Groves, 1984; Fooden et al., 1987) and its affinity with $H$. concolor is doubted. Its current status is unknown.

\section{China}

The only populations of black-crested gibbons that are known to be effectively protected are in China and even here numbers have been greatly reduced in recent years. The large population of $H$. c. hainanus that once inhabited

Table 1. Natural reserves for protection of black-crested gibbons

\begin{tabular}{|c|c|c|c|}
\hline Reserve & Area $(\mathrm{sq} \mathrm{km})$ & & Location \\
\hline Bawanglin Mountain reserve & 21 & & Hainan Island \\
\hline Wuliang Mountain reserve' & 350 & & Jingdong Co., Yunnan \\
\hline Ailao Mountain reserve ${ }^{1}$ & 550 & & Jingdong, Xinping, etc., Yunnan \\
\hline Huanglian Mountain reserve ${ }^{\mathrm{I}}$ & 138 & & Luchun Co., Yunnan \\
\hline Yunnan Daxue Mountain reserve & 158 & $?$ & Yongde Co., Yunnan \\
\hline Dawei Mountain reserve ${ }^{2}$ & 150 & $?$ & Hekou \& Pingbian Co., Yunnan \\
\hline Jinping reserve $e^{2}$ & 110 & $?$ & Jinping Co., Yunnan \\
\hline Weiyuan River reserve & 78 & $?$ & Jinggu Co., Yunnan \\
\hline Laojun Mountain reserve & 45 & $?$ & Ma Guan Co., Yunnan \\
\hline Nangun River reserve ${ }^{2}$ & $70^{*}$ & $?$ & Cangyuan Co., Yunnan \\
\hline Cuc Phuong National Park & $100+$ & $?$ & Vietnam \\
\hline Tam Dao & 170 & $?$ & Vietnam \\
\hline Muong Cha NR (Muong Te) & 1100 & $?$ & Vietnam \\
\hline Xuan Nha NR & 500 & $?$ & Vietnam \\
\hline Nam Dun NR & 140 & $?$ & Vietnam \\
\hline Chiem Hao Nahang NR & 60 & $?$ & Vietnam \\
\hline Xuan Son NR & 30 & $?$ & Vietnam \\
\hline Sop Cop NR & 40 & $?$ & Vietnam \\
\hline Trung Khanh NR & 30 & $?$ & Vietnam \\
\hline Ba Vi HCR & 20 & $?$ & Vietnam \\
\hline Ba Be HCR & 40 & $?$ & Vietnam \\
\hline Cam Son & (46) & $?$ & Vietnam \\
\hline Lien Son & $(1200)$ & $?$ & Vietnam \\
\hline Pia Bioc & $(100)$ & $?$ & Vietnam \\
\hline Thac Ba & $(40)$ & $?$ & Vietnam \\
\hline Yen Tu & $(40)$ & $?$ & Vietnam \\
\hline
\end{tabular}

1 Yang et al, in press.

2 Ma and Wang, 1986; Peng Yen-Chang, pers. comm.

? Presence of black-crested gibbons not confirmed.

* Mostly lar gibbons. Only a portion if any of this reserve contains black-crested gibbons.

+ Of the $250 \mathrm{sq} \mathrm{km}$ of this reserve, only $100 \mathrm{sq} \mathrm{km}$ remains in primary forest (Constable, 1982; Pfeiffer, 1984). All other areas for Vietnam represent habitat areas of reserves as demarcated or as proposed (in parentheses) and listed in MacKinnon and MacKinnon, 1986 or from IUCN data, 30 March 1989. Chinese reserve sizes as reported in Tang, 1987. 
Hainan Island (Figure 1) has been reduced to 16 individuals in the 2100-ha Bawanglin Reserve (Liu et al., 1987; King and Liao, in press; V. Drake, pers. comm.). It has been suggested that this subspecies once occurred on the mainland in southern China and in northern Vietnam (Dao, 1983; Fooden et al., 1987). On the mainland gibbons are now found only in Yunnan Province in widely scattered isolated populations in natural protected areas (Table 1 and Figure 2). Gibbons also occur in timber reserves, but only in the remotest parts (Yang et al., in press).

We recently had the opportunity to extend earlier survey work (Haimoff et al., 1986) in the two largest gibbon reserves: the Wuliang Mountain and Ailao Mountain reserves. We were interested to discover whether these were suitable for sustaining viable populations in the long term.

\section{The study sites}

The Wuliang Mountain and Ailao Mountain Natural Protected Areas are both narrow strips running along the tops of two parallel mountain ridges about $40 \mathrm{~km}$ apart (Figure 3 ). The Wuliang Mountain reserve is $55 \mathrm{~km}$ long and less than $9 \mathrm{~km}$ wide at its widest point, with a total area of 35,000 ha. The Ailao Mountain reserve covers 55,000 ha but is less than $6 \mathrm{~km}$ wide at its widest point and is 100 $\mathrm{km}$ long. Both rise from $1800 \mathrm{~m}$ to over $3300 \mathrm{~m}$ a.s.l., spanning mid-subtropical to temperate climatic zones. Below $1900 \mathrm{~m}$ pines are dominant, most of them planted; above this is tropical semi-deciduous forest, quite distinct from the tropical forest usually associated with gibbons (see Gittins and Tilson, 1984 for classification). Important tree families include Betulaceae, Fagaceae, Theaceae, Magnoliaceae,

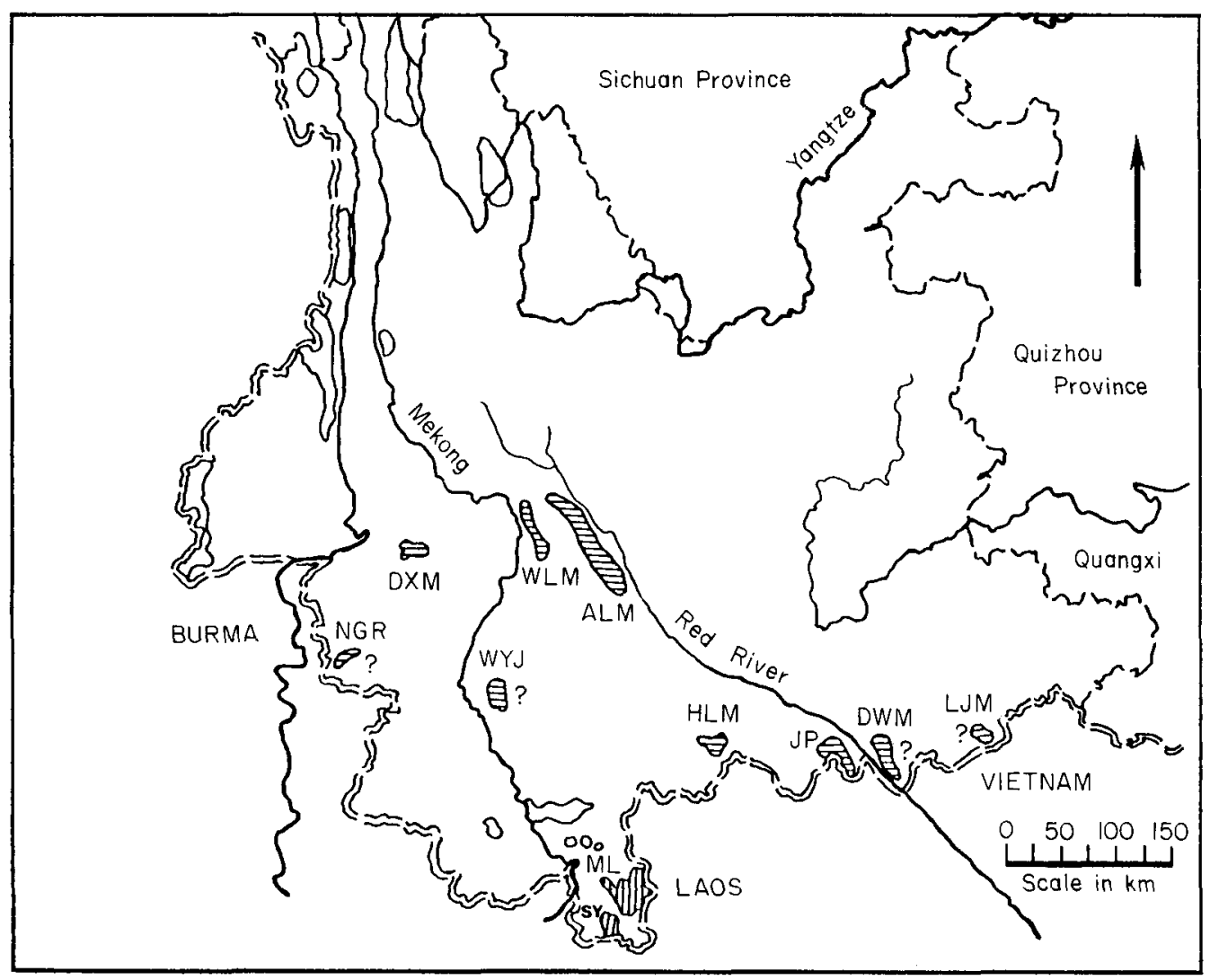

Figure 2. Some of the natural protected areas of Yunnan Province. 
Lauraceae and Ericaceae. Dominant trees include Castanopsis orthocantha, Lithocarpus spp., and Schima argentea. This is a distinct relict forest type, which has many affinities with the relict forest of the Smoky Mountains of North America, and the two regions share several taxonomic groups, including the genus Liriodendron (tulip trees). Other vertebrates of interest include macaques (probably Macaca arctoides, J. Fooden, pers. comm.), Phayre's leaf monkey Trachypithecus phayrei, slow loris Nycticebus coucang, giant flying squirrel and silver pheasant Lophura nycthemera. This interesting ecosystem is protected in only a few reserves, the largest of which are the Ailao and Wuliang. Despite the similarities of the two reserves, the Ailao Mountains are the eastern boundary for several species and subspecies, and the species composition is significantly different from that of the Wuliang range. Ma and Wang (1986) have suggested that the pelage of the gibbons in the Wuliang Mountains differs sufficiently from that of gibbons to the east to warrant their designation as a distinct subspecies, H. c. jingdongensis.

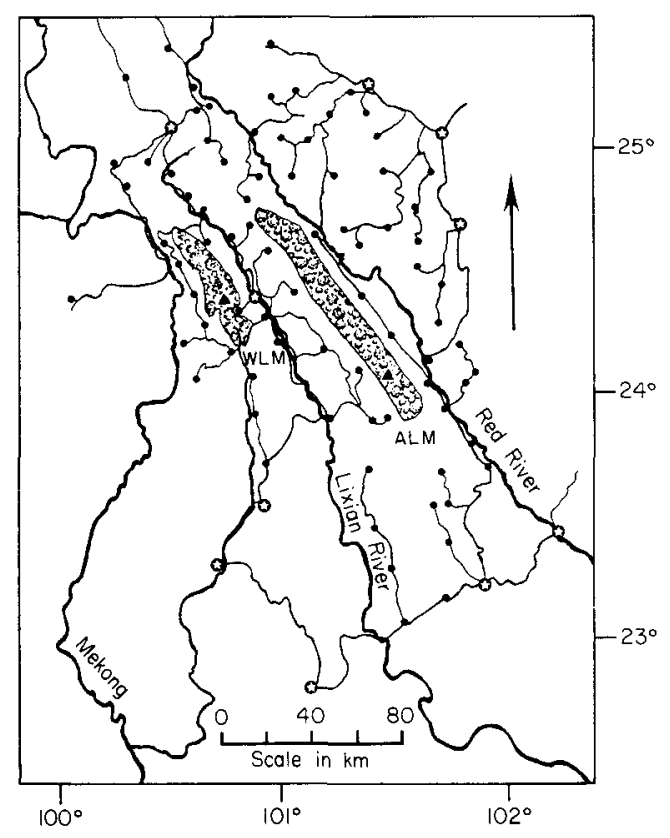

Figure 3. Wuliang Mountain and Ailao Mountain reserves showing major villages, roads and rivers.
The Ailao and Wuliang reserves are separated by the densely populated valley of the $\mathrm{Li}$ Xian River. Formerly this was one of the more remote regions of China; Ailao means 'miserable prison' in Mandarin. The region is also notable for a high proportion of ethnic minority people in the population. In addition to the Han, China's dominant ethnic group, the region is inhabited by Dai minority, who grow rice in the river valleys, and Yi minority, who terrace and farm the slopes. During the Great Leap Forward many Han Chinese settlers were moved into the area, relocating from land-starved areas. This, in combination with growth of the local population and government-sponsored programmes for rural development, resulted in rapid transformation of the landscape. These once remote reserves are now completely surrounded by a network of roads and villages (Figure 3 ).

\section{Threats to the gibbons}

Despite the fact that gibbons have been designated first-class protected animals by the Chinese Government, enforcement of the law is lax and hunting continues even within reserves. Many local people claim to be unaware that the wildlife in the reserves is protected by law. Shot and powder are cheap and easy to obtain, although most hunters have only single-shot muzzle loaders. Many local people still rely on muntjac and wild pig from the reserves as the main source of meat in their diet. Yi hunters living on the boundary of the Ailao reserve informed us that they shoot every time they see a gibbon, since it makes a good meal. In Wuliang Mountain reserve, however, expert local hunters claimed they no longer dare to shoot gibbons 'even if they cross right over our heads'. This may be in part because of a case in 1985, the only known to us, in which a hunter was arrested, successfully prosecuted and fined 400 yuan (about half a year's wages for many local people) for shooting a single gibbon. This incident was well known around this reserve. It is impossible to say if hunting of gibbons has actually decreased or if it has simply become 
less open. In at least one case, an entire group of gibbons living near a settlement disappeared between censuses in June 1985 and February 1987, although the forest had not been disturbed.

Habitat destruction is the other main threat to the gibbons. In both reserves illegal tree felling and land clearance for farming continues, often spreading across the reserve boundaries from adjacent fields. In many areas, which are not now under cultivation, forest has been replaced by a short scrub of bracken and bamboo, with sparsely scattered thickbarked trees and shrubs. This kind of vegetation is probably maintained by fires, either accidental or deliberately set to improve grazing for cattle. As recently as 1987 cattle herders were sold permits to set grass fires within the Wuliang Mountain reserve. It seems likely that dry season fires are gradually encroaching on the forest as forest edges become less humid and therefore less resistant to burning.

\section{How many left?}

Surveys were carried out in both reserves in 1985 and 1987. Some of these results have been published elsewhere (Haimoff et al., 1986). We travelled around the perimeter of the reserves interviewing local people about the state of the forest and the 'monkeys' that they were familiar with. In most areas, we were told that gibbons were once common, but could be found now only in the middle of the reserve. For example, in the village of Mo Dao $\mathrm{He}$, near the Wuliang reserve, villagers said that in the 1960s they could use the morning songs of the gibbons as an alarm clock, even from within the village. Now even hunters from this village who often travel into the forest said they never hear gibbons.

Surveys from roads or near villages may introduce a serious bias into density estimates, since these areas are often the most disturbed and subject to the most hunting (Brockelman and $\mathrm{Ali}, 1987)$. We therefore trekked into the

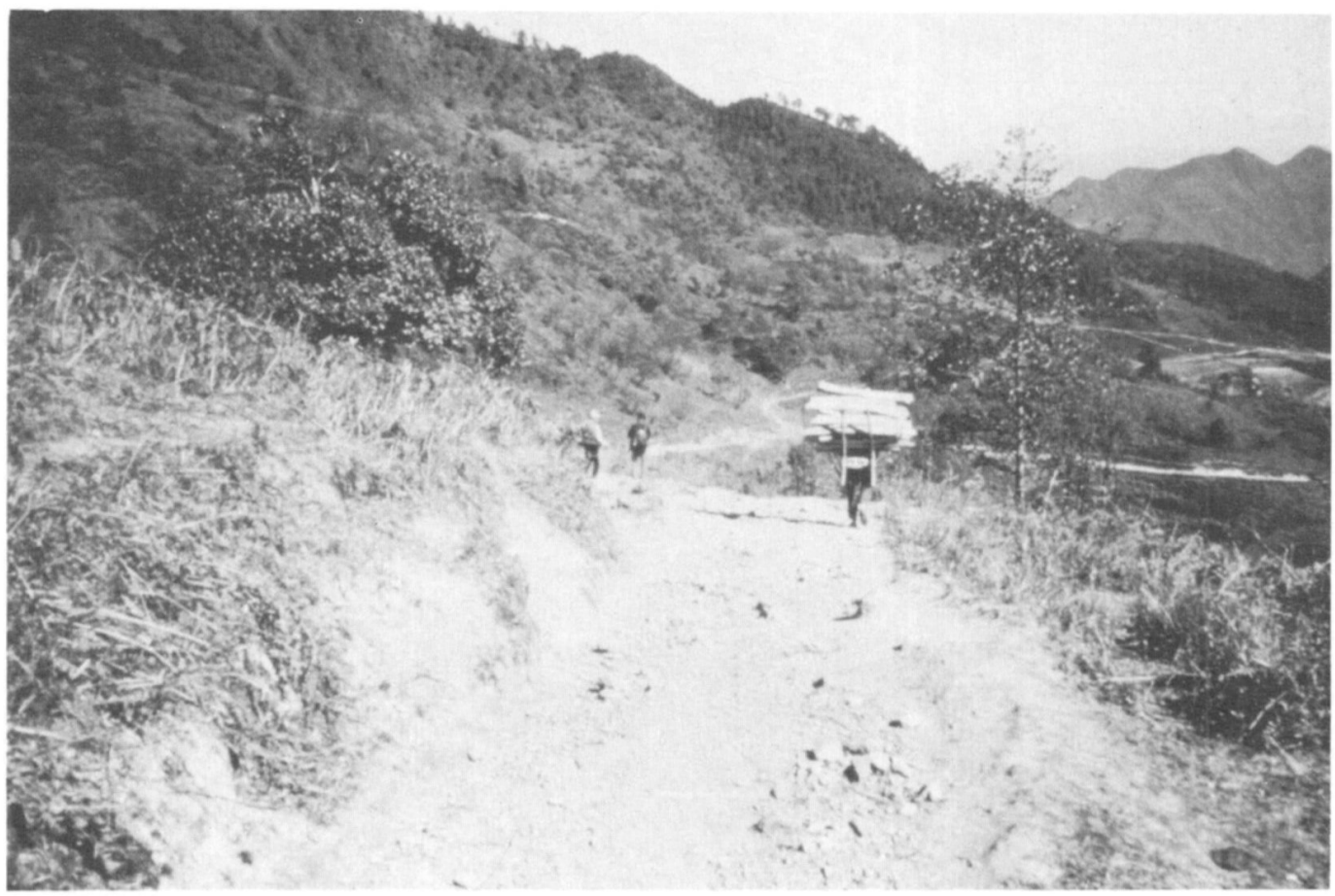

Firewood being carried down from Wuliang Mountain reserve. The surrounding landscape, with planted pines, is typical of the areas outside the reserve (W. Bleisch). 
reserves on foot, noting the location and condition of the forest and making censuses of the gibbons. Forest primates are very often difficult to survey visually, especially species that live in small groups, such as gibbons. In addition, hunting has made the gibbons extremely wary of humans. During the 30 man-days spent in forest definitely known to contain gibbons, we saw gibbons only five times. Luckily, gibbons produce a distinctive and localizable song on most mornings, which, if the terrain is favourable, can be heard as far away as $2 \mathrm{~km}$. By estimating the area of suitable habitat from which calls would be expected to be audible (defined by ridges) an estimate of the density of gibbon groups can be obtained (Brockelman and Ali, 1987). This sampling method is not biased by the low visibility of small groups, and it is much more efficient than other survey methods.

Land within the reserves can be roughly classified into four categories (Table 2): areas where deforestation has destroyed the closed canopy forest; areas where closed canopy forest is readily accessible to hunting and other disturbance; areas with good gibbon habitat, but which are recovering from past disturbance; and areas of undisturbed forest. We estimated gibbon densities in each category by performing auditory surveys at representative sites. For example, an area we surveyed in the Ailao Mountain reserve in the third category had been the site of a village, which was abandoned before the 1890s. More recently, part of the forest was logged, but no recent felling has occurred. Hunters continue to visit the area, but the presence of the coveted sambar Cervus unicolor suggests that hunting pressure is not severe. Gibbons were common in this watershed; in 7 days we heard four gibbon groups, of which an average 2.3 sang each morning. Based on a 72 per cent probability of any one group singing each morning (calculated from repeated sampling of three groups), we estimate that an average of 3.2 groups were within audible range each day. Since our listening sampled an area of at least $1.7 \mathrm{sq} \mathrm{km}$ of forest, we calculate a maximum density of 1.9 groups per sq $\mathrm{km}$ of forest in this area (Brockelman and Ali, 1987). This relatively high density sug- gests that gibbons may have been concentrated by habitat destruction, perhaps the result of recent grass fires encroaching into the forest. Using the same methods, we derived density estimates for representative sites in all categories (Table 2).

How many gibbons remain in the two reserves? Estimates vary from 10-11 groups in both reserves (Tan, 1985) to 200-250 groups in Wuliang Mountain reserve alone (Haimoff et al., 1987). More recently Yang et al., (in press), estimated 75 groups in the Wuliang Mountain and Ailao Mountain areas combined.

Our own estimates are based on the estimates of the amount of each reserve in the various categories. We estimate that of the 35,000 ha in Wuliang Mountain reserve, less than 25,000 ha has closed canopy forest suitable for gibbons and less than 50 per cent of this is remote enough to have gibbon density as high as 1 group per sq $\mathrm{km}$. From this, we estimate the total number of gibbon groups in Wuliang Mountain reserve to be 160, and certainly fewer than 300 groups. The Ailao Mountain reserve has 40,000 ha of closed canopy forest, but since much of this reserve is more accessible to hunters than Wuliang, there may be about the same number of groups in Ailao, despite its larger total area.

How many black-crested gibbons remain in China? Yang et al. (in press), on the basis of interviews with local hunters and foresters and first-hand observations throughout China, suggest that gibbons are already extremely rare outside existing natural protected areas. If other natural protected areas are in similar condition and have similar gibbon densities to Wuliang and Ailao Mountain reserves, then we estimate that there are 350-1100 gibbon groups in $1670 \mathrm{sq} \mathrm{km}$ of natural protected areas in China.

Extrapolating from estimates of numbers of groups to numbers of individuals and ultimately to effective population size requires data on group size and composition. Gibbons in China have been heavily hunted and are extremely wary of observers, so it is difficult to obtain good observations of entire groups. Combining our recently collected data with that presented in Haimoff et al. (1986) we find 
Table 2. Summary of areas surveyed by condition, with gibbon densities and area of the reserves in each category

\begin{tabular}{llcll}
\hline Forest cover & Open & Closed canopy & Closed canopy & Closed canopy \\
Type of disturbances & $\begin{array}{l}\text { Farming, } \\
\text { fire }\end{array}$ & $\begin{array}{l}\text { Hunting, tree- } \\
\text { felling, grazing }\end{array}$ & $\begin{array}{l}\text { Recovering from } \\
\text { past disturbance }\end{array}$ & Undisturbed \\
\hline Area surveyed (sq km) & $>10$ & $7+2$ & 1.7 & $3.2+5$ \\
Gibbon densities (groups $/ \mathrm{sq} \mathrm{km)}$ & 0 & 0.2 & 1.9 & 1.3 \\
Area of Wuliang Mt. reserve $(\mathrm{sq} \mathrm{km})$ & 100 & 125 & & 125 \\
Area of Ailao Mt. reserve $(\mathrm{sq} \mathrm{km})$ & 150 & 275 & & \\
\hline
\end{tabular}

a median group size in this species of five animals $(n=10)$, in agreement with recent data provided by Lan et al. (in press). This suggests an estimate of 1750-5350 black-crested gibbons in natural protected areas in China, mostly in populations with fewer than 400 individuals and fewer than 80 breeding males (Table 1).

Haimoff et al. (1986) suggested that blackcrested gibbons live in polygynous groups, unlike other species of gibbons that have been studied, all of which live in monogamous groups. Identifying polygyny unequivocally will require demonstrating that there are groups that contain multiple females with infants, and this will necessitate close observation. We suggest that the data available to date are consistent with other interpretations. For example, in the populations studied, subadult females may remain with their natal groups longer than in other populations because habitat fragmentation has made it extremely difficult for subadult gibbons to find suitable mates with which to establish new territories. The point is important for conservation considerations. If the species lives in monogamous groups, then the number of breeding females in a population would be roughly equal to the number of groups. On the other hand, if black-crested gibbons are polygynous, this would substantially increase estimates of the size of effective breeding populations. In addition, monogamous primates are more vulnerable to extinction at small population sizes than are promiscuous primates because of the increased difficulties females have contacting suitable mates (Dobson and Lyles, 1990).

\section{The future}

Perhaps more important than the exact number of gibbons currently in the reserves is the question of the viability of these populations. There can be little doubt that if deforestation and hunting continue at past rates, the gibbons of Wuliang Mountain and Ailao Mountain will be gone within the next decade, whatever their current numbers. Control of hunting and deforestation within the reserves is the key to preservation of this species.

A serious concern is whether the gibbons remaining in the reserves are already becoming isolated from each other in small patches of forest. For example, within the Wuliang Mountain reserve, an area of dense forest with many gibbons was found to be connected to the main forest by only two narrow forest corridors (Figure 4). Timber cutting by villagers to the north and fires set by cattle grazers living within the reserve are endangering these corridors. Once isolated, small populations of gibbons even if well-protected, are at risk because of loss of genetic diversity through inbreeding, as well as risk of extinction by a simple 'random walk' of population size (Gilpin and Soule, 1986). In many areas within the reserves, small, isolated populations of gibbons may already be below the minimum viable population size. If so, the future of the populations in these isolated patches is in jeopardy, and ultimately the populations of the entire reserve may be as well.

Despite this bleak picture, there is much cause for hope. Since February 1987, the Ministry of Forests has taken a new, aggres- 
sive stance towards protection of the reserves. At Wuliang Mountain reserve, 20 specially trained rangers have begun regular patrols. A campaign has been initiated to prevent fires and to educate local people that the animals and forest of the reserve are protected by law. Family planning measures are to be encouraged and immigration into some villages on the boundaries of the reserve is to be restricted. This may eventually ease the pressures on the forest by local people seeking firewood and land for farming. Hunting and carrying a gun into the reserve is no longer allowed. Finally, the Ministry has started a programme to improve the lives of local people who live in and around the reserve, in order to provide alternatives to wood-cutting, land-clearing and hunting. For example, the people of Huang Cao Lin are being encouraged to plant cash crops such as fruit trees, flower pepper (hua jiao) and tea. These last measures are particu-larly important. In some cases local people may have few products that they can sell besides firewood and no regular source of meat apart from what they can shoot.

With persistence, these measures may slow the destruction of the forest and the loss of its wildlife. To ensure the future of the gibbons, however, more strenuous measures will be required. The reserves as currently demarcated may be simply too difficult to protect effectively. Their elongated shape means that there is no well-protected central core, since the centre of the reserve is rarely more than $6 \mathrm{~km}$ from the nearest human settlement. The steep slopes on either side provide some protection, but several heavily used trails cut right across the reserves from east to west. Road building around and even inside the reserves continues, and construction has begun on a road from Kunming to Jing Dong and continuing on to the south-west, which will cut directly across both reserves, opening up areas that were previously remote. A recent report in the Chinese press indicates that gold has been discovered in the Ailao mountains. These changes can only increase the human pressures on the forest and add urgency to the need for strong conservation measures.

We recommend that the boundaries of the reserves should be expanded to include some of the lower elevation pine forest to serve as a buffer zone. Enlarging the reserves may reduce the cost of effective protection. Reforestation outside the reserves should also be a priority to provide an alternative source of firewood and lumber.

In addition to improving the protection of the existing forest, every effort should be made to encourage the regeneration of forest within the reserve in order to reconnect isolated populations of gibbons. Towards this end grass fires should be strictly prevented in the reserve, grazing must be restricted, firebreaks should be constructed in some strategic areas of grassland and trees should be planted.

Without vigorous measures such as these the future of the gibbons is precarious. Eventually $H$. concolor may exist only in zoos and in whatever well-protected natural populations still persist. Outside these protected areas habitat destruction and over-hunting seem certain to continue until all the gibbons are gone. Considering the size and the population estimates of gibbons in these and other

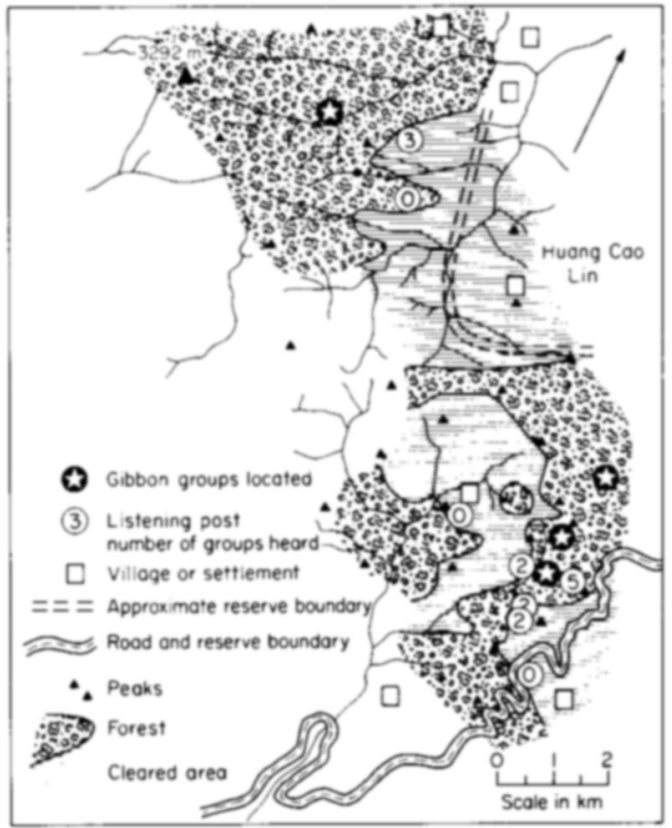

Figure 4. Southern portion of Wuliang Mountain reserve showing detail of survey area. Labelled peak in upper left is also shown in Figure 3. 
reserves, and the tenuous status of this species outside China, we believe that the Wuliang Mountain and Ailao Mountain reserves may be the best hope for the black-crested gibbon.

\section{Acknowledgments}

The authors wish to thank the Kunming Institute of Zoology and its director, Professor Shi Liming, and the China Exploration and Research Society and its president, How-Man Wong. Professor Peng Yanzhang, Kunming Institute of Zoology, provided invaluable advice during the course of the research. Drs Warren Brockelman, John Mitani, John Oates, and Mary Pearl provided helpful criticism on various drafts. Funding was generously provided by the Durfee Foundation as a China/America Adventure Capital Award to W.V.B.

\section{References}

Brockelman, W.Y. and Ali, R. 1987. Methods of surveying and sampling forest primate populations. In Primate Conservation in the Tropical Rain Forest (eds C. W. Marsh and R. A. Mittermeier) pp. 23-62. Liss, New York.

Constable, J.D. 1982. Visit to Viet Nam. Oryx, 16, 249-254.

Dao, V.T. 1983. On the north Indochinese gibbons (Hylobates concolor) (Primates: Hylobatidae) in North Vietnam. J. Human Evol., 12, 367-372.

Dobson, A.P. and Lyles, M. 1990. The population dynamics and conservation of primate populations. Conservation Biol. 3, 362-380.

Fooden, J., Quan G. and Luo, Y. 1987. Gibbon distribution in China. Acta Theriologica Sinica, 7, 161-167.

Gilpin, M.E. and Soule, M.E. 1986. Minimum viable populations: processes of species extinction. In Conservation Biology: The Science of Scarcity and Diversity (ed M. E. Soule) pp. 19-34. Sinauer Assoc., Sunderland, MA.

Gittins, S.P. and Tilson, R.L. 1984. Notes on the ecology and behaviour of the hoolock gibbon. In The Lesser Apes: Evolutionary and Behavioral Biology (eds H. Preuschoft et al.) pp. 258-266. Edinburgh University, Edinburgh.

Groves, C.P. 1984. A new look at the taxonomy and phylogeny of the gibbons. In The Lesser Apes: Evolutionary and Behavioral Biology (eds $\mathrm{H}$. Preuschoft et al.) pp. 542-561. Edinbirgh University, Edinburgh.
Groves, C.P. and Wang, Y.-X. 1988. The gibbons of the subgenus Nomascus. Symposium of Asian-Pacific Mammalogy, July 1988, Abstracts, p. 7. Haimoff, E.H., Yang, X.-J., He, S.-J. and Chen, N. 1986. Census and survey of wild black-crested gibbons (Hylobates concolor concolor) in Yunnan Province, People's Republic of China. Folia. Primatol. 46, 205-214.

Haimoff, E.H., Yang, X.-J., He, S.-J. and Chen, N. 1987. Conservation of gibbons in Yunnan Province, China. Oryx, 21, 168-173.

King, B. and Liao, W.-P. 1989. Hainan Island bird notes. Hong Kong Bird Watching Society Bird Report, (in press).

Lan, D., Shu, L. and He, S. In press. The preliminary observation on the group composition of the wild concolor gibbons (Hylobates concolor) in Yunnan China. Primate Report, in press.

Liu, Z., Jiang, H., Zhang, Y. Liu, Y., Chou, T., Manry, D. and Southwick, C. 1987. Field report on the Hainan gibbon. Primate Conservation, 8, 49-50.

Ma, S. and Wang, Y. 1986. The taxonomy and distribution of the gibbons in Southern China and its adjacent regions-with description of three new subspecies. Zool. Res. 7, 393-410.

Ma, S., Wang, Y. and Poirier, F.E. 1988. Taxonomy, distribution and status of gibbons (Hylobates) in southern China and adjacent areas. Primates, 29, 277-286.

MacKinnon, J. and MacKinnon, K. 1986. Review of the Protected Area Systems of the Indo-Malayan Realm. IUCN and UNEP.

MacKinnon, J. and MacKinnon, K. 1987. Conservation status of the primates of the Indo-Chinese subregion. Primate Conservation, $\mathbf{8}$, 187-195.

Marshall, J. and Sugardjito, J. 1986. Gibbon systematics. In Comparative Primate Biology, Volume 1: Systematics, Evolution and Anatomy. pp. 137-185. Liss, New York.

Pfeiffer, E.W. 1984. The conservation of nature in Viet Nam. Environ. Conserv. 11, 217-221.

Tan, B. 1985. The status of primates in China. Primate Conservation, 6, 63-81.

Tang, X. 1987. Zi Ran Bao Hu Qu Tan Sheng. New World Press, Beijing.

Yang, D.-H., Zhang, J.-Y. and Li, C. In press. A survey of the population and distribution of gibbons in Yunnan Province. Primates, (in press).

William Bleisch, China Exploration and Research Society, 4028 Chaney Trail, Altadena, CA 91001, USA.

Chen Nan, Kunming Institute of Zoology, Academia Sinica Kunming, Yunnan Province, China. 